\title{
Harnessing Geographic Information Systems (GIS) to Enable Community-Oriented Primary Care
}

\author{
Andrew Bazemore, MD, MPH, Robert L. Phillips, MD, MSPH, FAAFP, and \\ Thomas Miyoshi, MSW
}

Background: Despite growing acceptance and implementation of geographic information systems (GIS) in the public health arena, its utility for clinical population management and coordination by leaders in a primary care clinical health setting has been neither fully realized nor evaluated.

Methods: In a primary care network of clinics charged with caring for vulnerable urban communities, we used GIS to (1) integrate and analyze clinical (practice management) data and population (census) data and (2) generate distribution, service area, and population penetration maps of those clinics. We then conducted qualitative evaluation of the responses of primary care clinic leaders, administrators, and community board members to analytic mapping of their clinic and regional population data.

Results: Practice management data were extracted, geocoded, and mapped to reveal variation between actual clinical service areas and the medically underserved areas for which these clinics received funding, which was surprising to center leaders. In addition, population penetration analyses were performed to depict patterns of utilization. Qualitative assessments of staff response to the process of mapping clinical and population data revealed enthusiastic engagement in the process, which led to enhanced community comprehension, new ideas about data use, and an array of applications to improve their clinical revenue. However, they also revealed barriers to further adoption, including time, expense, and technical expertise, which could limit the use of GIS and mapping unless economies of scale across clinics, the use of web technology, and the availability of dynamic mapping tools could be realized.

Conclusions: Analytic mapping was enthusiastically received and practically applied in the primary care setting, and was readily comprehended by clinic leaders for innovative purposes. This is a tool of particular relevance amid primary care safety-net expansion and increased funding of health information technology diffusion in these settings, particularly if the hurdles of cost and technological expertise are overcome by harnessing new advances in web-based mapping technology. ( $\mathrm{J}$ Am Board Fam Med 2010;23:22-31.)

Primary care clinics and the patients they serve are bound to one another by geography. In the case of community health centers (CHCs), policies tie clinics to geography via the federal designations of medically underserved areas (MUAs) or health professional shortage areas; financial incentive is provided to clinics located within these areas. However, planners and clinicians often assume or ignore the characteristics of these primary care geogra-

This article was externally peer reviewed.

Submitted 27 April 2009; revised 26 August 2009; accepted 8 September 2009.

From The Robert Graham Center (AB, RLP), Washington, DC; and the Arkansas Center for Health (TM), Little Rock, AR.

Funding: none.

Conflict of interest: none declared.

Corresponding author: Andrew Bazemore, MD, MPH, The Robert Graham Center, 1350 Connecticut Ave., NW, Suite 201, Washington, DC 20036 (E-mail: abazemore@aafp.org). phies, fail to use utilization data to evaluate their assumptions, and rarely study or use them in the process of planning clinical services by $\mathrm{CHCs}$ or other private outpatient providers. To efficiently plan new clinic locations and improve access to care for vulnerable populations, it is critical to understand existing clinical service areas and patterns of service utilization, particularly amid 3 concurrent national trends: growing numbers of uninsured, rapid expansion of $\mathrm{CHCs}$, and the likelihood of a mandated insurance requirement increasing the burden on existing primary care providers. ${ }^{1,2}$ One potential tool for understanding access to and utilization of care is geographic information systems (GIS), which permit the combination of many data sources into dynamic analytic maps; these are increasingly implemented in the public health sector. ${ }^{3}$ However, although GIS has been used by health services researchers and epidemiologists to 
study populations to better understand cancer epidemiology, disease outbreaks, and even the impact of distance on care, there is little known about GIS applications using clinical data or measuring access to and utilization of care at a community level. Specifically, few studies have demonstrated the ability of GIS to better understand access to primary health care. ${ }^{4-7}$

Although combining CHC data with existing population data using GIS has been reported, its usefulness and barriers to and means of expanding the use of GIS among clinical and community leaders of CHCs has not been thoroughly evaluated. ${ }^{8-10} \mathrm{We}$ applied qualitative methods to investigate in depth the perspectives and responses to mapping clinical and population data in a real community health setting, exploring with CHC leaders the barriers to and opportunities for implementation of this powerful technique.

\section{Methods}

This study used informant interviews and focus group techniques to evaluate a collaborative community-based project between Baltimore Medical System, Inc. (BMSI) and the Robert Graham Center for Policy Studies in Family Medicine and Primary Care. It was approved by the Georgetown University Medical Institutional Review Board.

\section{Study Setting, Community Project Description, and Data Sources}

We extracted from practice management software a comprehensive dataset of the nearly 30,000 patients who had visited a system of 7 federally qualified $\mathrm{CHCs}$ in 2003. At the time the system of clinics employed more than 40 primary care providers in the service of indigent patients in urban and periurban Baltimore, Maryland. We cleaned and geocoded all clinical data representing unique patients during a single year period, achieving an $80 \%$ geocoding match rate. Using ArcView GIS software (ESRI, Redlands, CA), we integrated the geocoded clinical data with US Census data and other publicly accessible spatial information to create simple analytic maps and outputs in a variety of formats. To reveal neighborhood utilization patterns for each clinic and to create individual clinic and system-wide service area maps, we reviewed possible spatial techniques, selected a modified Griffith's commitment index and evaluated methods previously described in the limited primary care literature on the subject (see Figure 1). ${ }^{11}$ The index measures the degree of patient utilization of a clinic from individual geographies-in this case all census block groups or tracts containing patients from the clinics that were studied. Tracts were ranked by index in descending order and were included in the overall clinic or system-wide service area only until $60 \%$ of all patient data were included. Maps of the designated MUA for a clinic were also generated (Figure 2) to demonstrate differences between federally intended and utilization-derived (actual) service areas. We additionally plotted patient and subpopulation distribution maps and calculated area penetration rates for each clinic (see Figure 3), which were defined by the number of yearly clinic users per total population in each census tract according to the 2000 Census. Our methods are described in greater detail elsewhere. ${ }^{10}$ These maps were then presented to BMSI clinicians and leaders as a series of focus groups and in-depth interviews designed to evaluate the utility of analytic mapping in a primary care setting and the potential for and barriers to broader application.

\section{Qualitative Data Collection and Analysis}

With the help of BMSI administrative staff, we assembled our sample from the leadership of BMSI, including clinicians, administrators, staff representing potential constituents of mapped data, and community board members. The organizational knowledge of an investigator who had previous knowledge of BMSI as a clinician, coupled with queries of network leaders, was used to ensure that leadership from all BMSI divisions and the community it served were represented when key informants and group participants were selected. ${ }^{12}$ Data were assembled using 3 qualitative methods: (1) as participant observers in a longitudinal interaction with BMSI and its staff, (2) through key informant interviews with selected clinicians and administrators most involved with the management of the organization, and (3) through focus groups with those most involved in the strategic planning and operations of BMSI. Participant observation was used to capture participant reactions to our mapping project and to gather comments about how an organizational culture views and embraces or rejects a new technology such as this. ${ }^{13}$ Key informant interviews helped us understand the per- 
Figure 1. Baltimore Medical Systems, Inc.'s' aggregate service area. Using billing and administrative data assigned to clinic, this map shows the service area (census tract) of 4 BMSI clinics and their overlap.

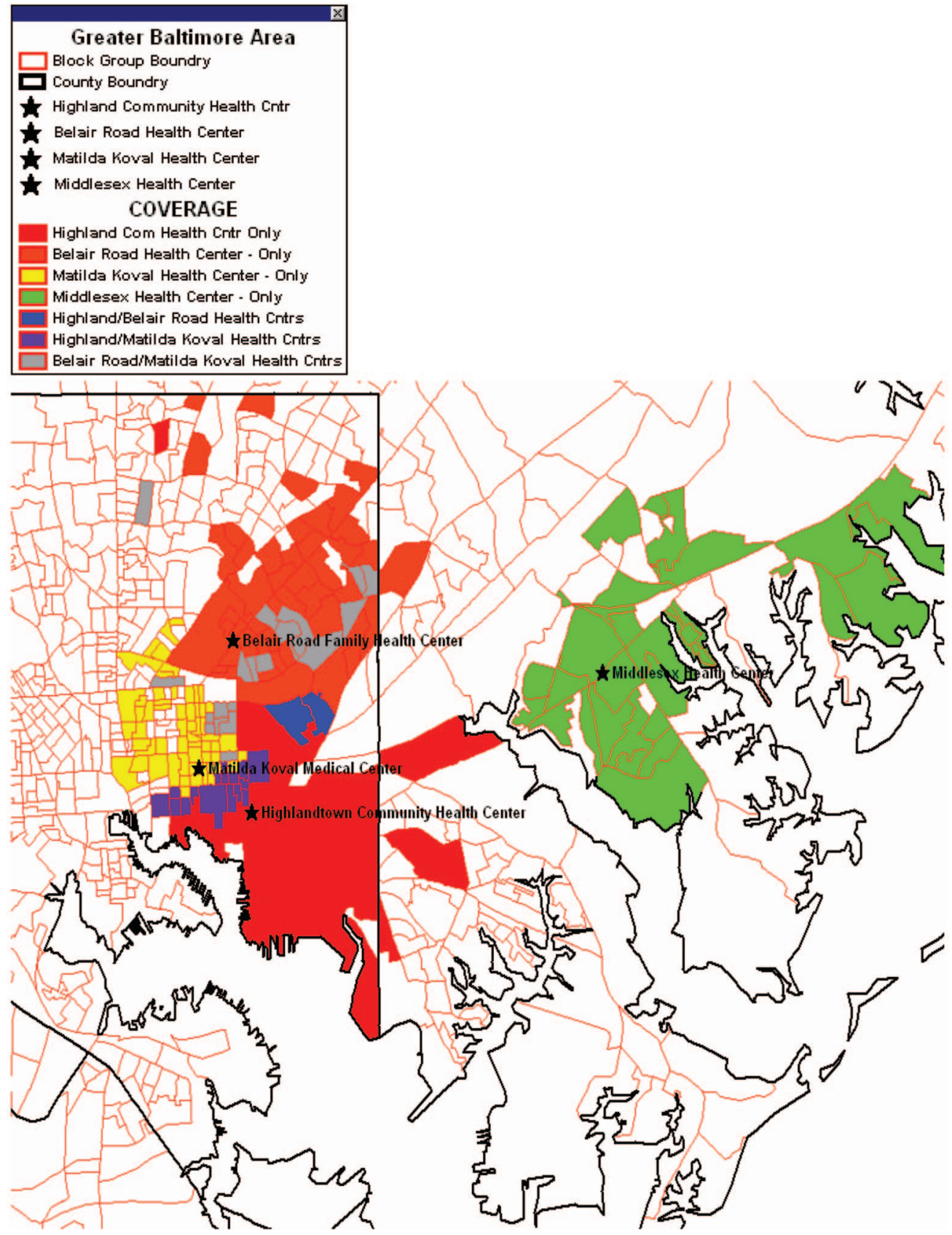

spectives of individuals with essential but distinct roles within the organization, in this case the Chief Executive Officer, the Chief Medical Officer, the Chief Operating Officer, and the Director of Community Outreach. Focus groups provided a broad array of perspectives from clinician leaders (eg, the physician directors of pediatric and adult medicine), nursing leaders, ancillary services leaders, community liaisons, administrators, and represen- tatives of the communities directly served by BMSI. They also permitted capture of group responses to, spontaneous conversations and discussions about, and interactions over analytic mapping. The small sampling frame of BMSI leaders limited our focus groups to 2: one with members of the Clinical Operations Committee (10 attendees) and the other with members of the Community Advisory Board for BMSI (5 attendees). 
Figure 2. This map demonstrates the federally designated medically underserved area that a single Baltimore Medical Systems, Inc., clinic receives federal funding to serve, with quarter-mile radii from clinic marked out to 2 miles. Discrepancies between maps of these "ideal" service areas and the actual service areas (such as that in Figure 1) were cited by BMSI executives as informative and surprising; they later used the actual service area information to change a relocation decision based previously on medically underserved area alone.

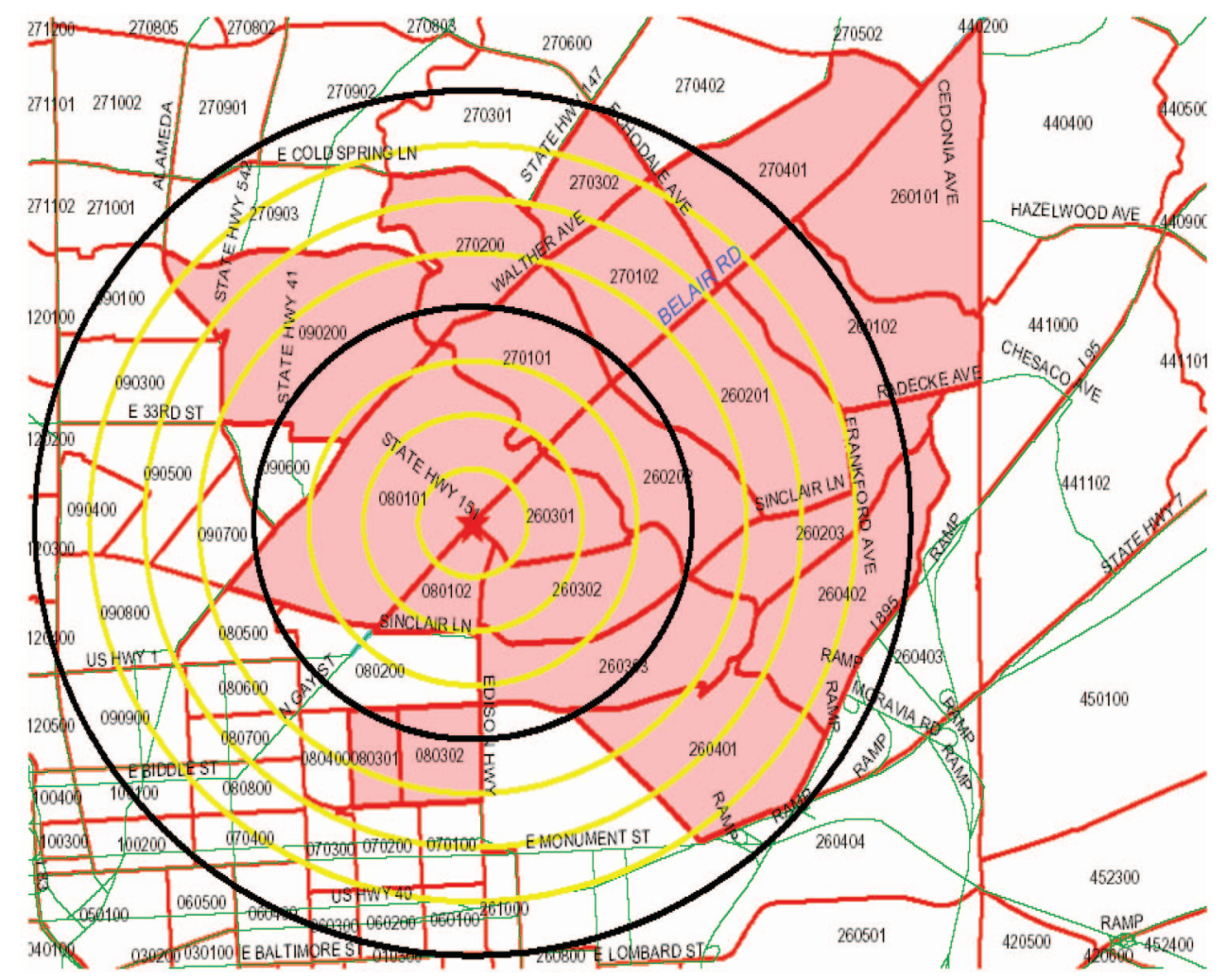

Each session began with a short summary presentation of project background, maps, and details of the collaboration to date, followed by a semistructured query to assess 4 domains of interest: (1) understanding of the analytic mapping process, (2) interpretation of the data presented, (3) perceived usefulness of analytic mapping for strategic planning and delivery of improved services in the primary care outpatient setting, and (4) barriers to and enablers of continued use of these methods. Clarifying and additional questions were asked based on participant responses. Key informant interviews were similarly structured, with additional questions tailored to the informant's position within the organization. All information was recorded and later transcribed. In each interview and focus group, one interviewer recorded responses while the other guided the presentation and interview. Investigators alternated between presentation/querying and note taking to ensure a more robust set of observations and information recording. Thematic anal- ysis of transcriptions and interview notes were reviewed by 2 of the investigators (AB and RLP) and then discussed until consensus was reached regarding common themes. The project was approved by the Georgetown Institutional Review Board.

\section{Results}

With minimum explanation and a brief iterative exchange, BMSI administrators and their information technology support team were able to produce a comprehensive, 1-year, patient-level database for analysis. Geocoding yielded an $80 \%$ first-pass match. Service area maps revealed previously unrecognized range and overlap of individual clinical services (Figure 1), whereas MUA/service area match and area penetration densities varied widely by clinic (Figures 2 and 3). As qualitative reporting revealed (below), dynamic mapping and static maps-such the samples seen in the figureshelped BMSI leaders identify and strategize around 
Figure 3. Census tract population penetration rate for a single Baltimore Medical Systems, Inc., clinic. Revealing dense utilization (as high as $30 \%$ of the population) by persons in the census tracts most proximal to this clinic, these maps were cited as critical to strategic planning for future expansion and service delivery. GIS, geographic information systems.
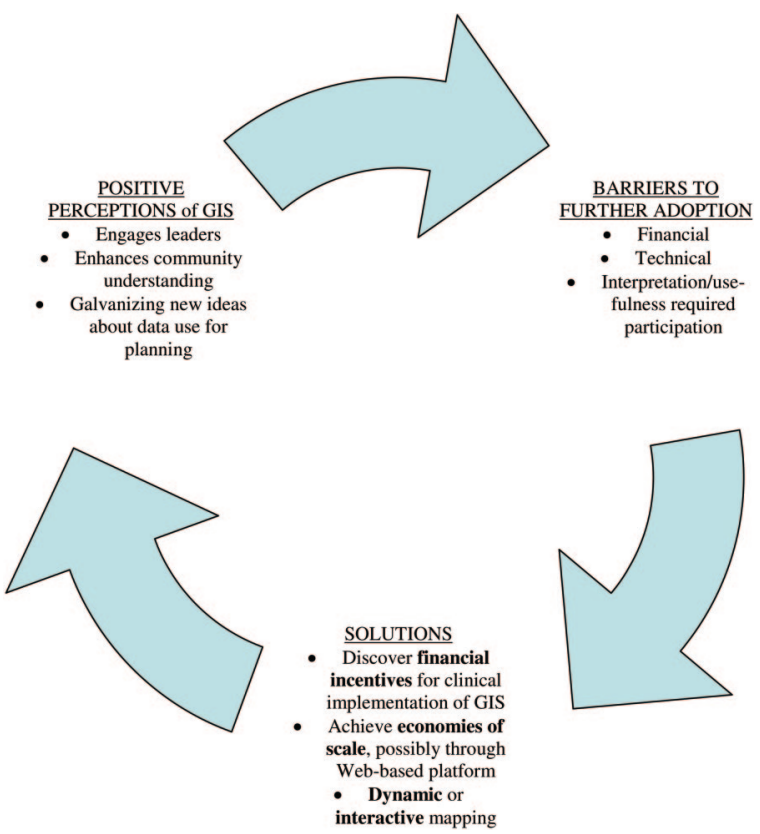

unrecognized patterns of clinic use, including unexpected use by remote populations. They also revealed the geographic dimensions of BMSI's primary care services and the extent to which the communities they served depended on their clinics for primary care services.

Initial qualitative analysis revealed the following 7 central themes and perceptions:

1. Mapping and spatial analysis of clinical data resulted in engagement of busy administrators and clinicians. Responses were enthusiastic regarding the potential of analytic mapping to help guide CHC strategic planning and resource allocation.

2. Participants reported enhanced community comprehension as a result of analytic mapping and were, in fact, better suited to interpreting their mapped clinic data than the investigators; interviewees stated a ready understanding of health service area and penetration maps. Many offered suggestions about how to make the maps more easily interpretable that neither presenting investigator had considered. Both investigators also noted that participants could easily grasp the limitations of mapped data and were quick to recognize the perils of overinterpretation of map data in isolation. Participants from the Clinical Operations Committee were visibly engaged in the presentation portion of the focus group, interrupting the authors repeatedly with queries and suggestions. Both investigators noted that committee members had visible epiphanies ("a-ha moments") when they saw certain maps. After presenting aggregate BMSI service area maps (Figure 1), the presenters were interrupted by multiple participants at once, as if the maps had unveiled a mystery. During the 6 months after our interviews, participants requested a number of additional maps to support a BMSI application to expand that clinic.

3. Participatory interpretation of mapped clinic data was essential and was deeply enriched by provider and administrator knowledge of their patient population. Participant knowledge was essential to and revealed through the analytic map interpretation process. As noted above, interviewees applied their experience and local knowledge to interpret service areas. However, multiparty interaction between technical staff, administrators, clinicians, and community members allowed the unique knowledge and expertise of each-whether in data, neighborhood geographies, community history, or other areas-to capture the real power of mapped data. Energy was highest in the group settings, and investigators were struck by how essential local knowledge was to interpreting clinical and community maps relative to tables, graphs, and other forms of data frequently reviewed in these settings. In both focus groups, considerable and far-ranging knowledge of socioeconomic status and social capital among participants was revealed amid animated discussions of why maps showed variable service penetration by African-Americans in specific neighborhoods.

4. Mapping existing and previously dormant practice management data in this fashion galvanized new ideas about data use for strategic planning and population management. CHC leaders and staff quickly and enthusiastically generated a list of additional spatial analyses 
that they desired to improve their operations. Further, this phenomenon was not limited to selected individuals; staff from each administrative and clinical unit of the CHC network was able to identify a potential analytic mapping project of value to them. The participatory process generated numerous practical applications for analytic mapping that the investigators had not considered.

5. Mapping was identified as having the capacity to support clinic financing and resource allocation. Leaders and clinicians were most enthusiastic about using analytic mapping to support the expansion of grant applications and clinical operations and to impact the effectiveness of patient outreach.

6. Financial and technologic issues were perceived barriers to project sustainability. Many participants cited concerns that the expense and manpower involved in analytic mapping at the desktop would limit their long-term use of this technology without continued outside assistance. Specifically, they lamented their limited information technology infrastructure and staff expertise in the use of analytic mapping software.

7. Achieving economies of scale across clinics and with foundation or federal support and capturing the power of dynamic mapping through web technology were reported as the best ways to overcome the barriers mentioned above. Participants noted that their likelihood of using clinical data mapping would be far greater if overworked staff had immediate access to their data and the power of GIS when they had a specific question related to mapping. Participants also noted that such a tool should be flexible enough to incorporate other community and population data and to expand into other mapping applications useful to the primary care enterprise.

Investigators further sorted these themes into 3 principal domains of findings: (1) perceptions of primary care implementation of GIS (mostly positive), (2) barriers to further implementation, and (3) possible solutions (see Table 1 for examples and Figure 4 for a summary schematic).

\section{Discussion}

The profound effects of neighborhoods and community on health are well documented. ${ }^{14}$ Despite this and continuing calls to understand their patients in the context of community and place, ${ }^{15-18}$ most clinicians lack the tools to evaluate and display that community context. In this study we tested novel GIS use in an urban primary care network and demonstrated and categorized the value of analytic mapping to primary care outpatient leaders in identifying community context. Readily available primary care clinical data were easily combined with population data within a GIS environment to understand communities, and clinical leaders affirmed the value of this process for populationbased care and planning. Outpatient clinic leaders, clinicians, and community board members in our study were engaged and galvanized by the power of mapped data to enhance community care, and they easily identified applications of analytic mapping that would improve their clinical operations.

Any primary care setting or clinical enterprise could potentially benefit from the techniques described here and previously, in particular the expanding primary care safety net. ${ }^{19,20}$ Clearly articulated statements about the value of these tools to clinic and community leaders were couched against the need for less technical and time-intensive processes-processes that could permit secure, interactive queries of mapped clinic and population data, because there is a dearth of tools able to inform primary care leaders about access and utilization patterns at the practice and community levels. On a national level, federal funding initiatives to expand health information technology, regional health information organizations, and uniform data set collection in primary care safety nets are encouraging opportunities for diffusion of analytic mapping in the primary care setting. ${ }^{21}$ Tools are needed more than ever to guide the continued expansion of federally qualified health centers and to identify gaps in safety-net coverage A secure, web-based mapping tool that is broadly implemented in outpatient health centers would complement Health Resources and Services Administration efforts to offer all Americans a "medical home" through projects such the Models That Work campaign and the Primary Care Service Area project. $^{22,23}$ 


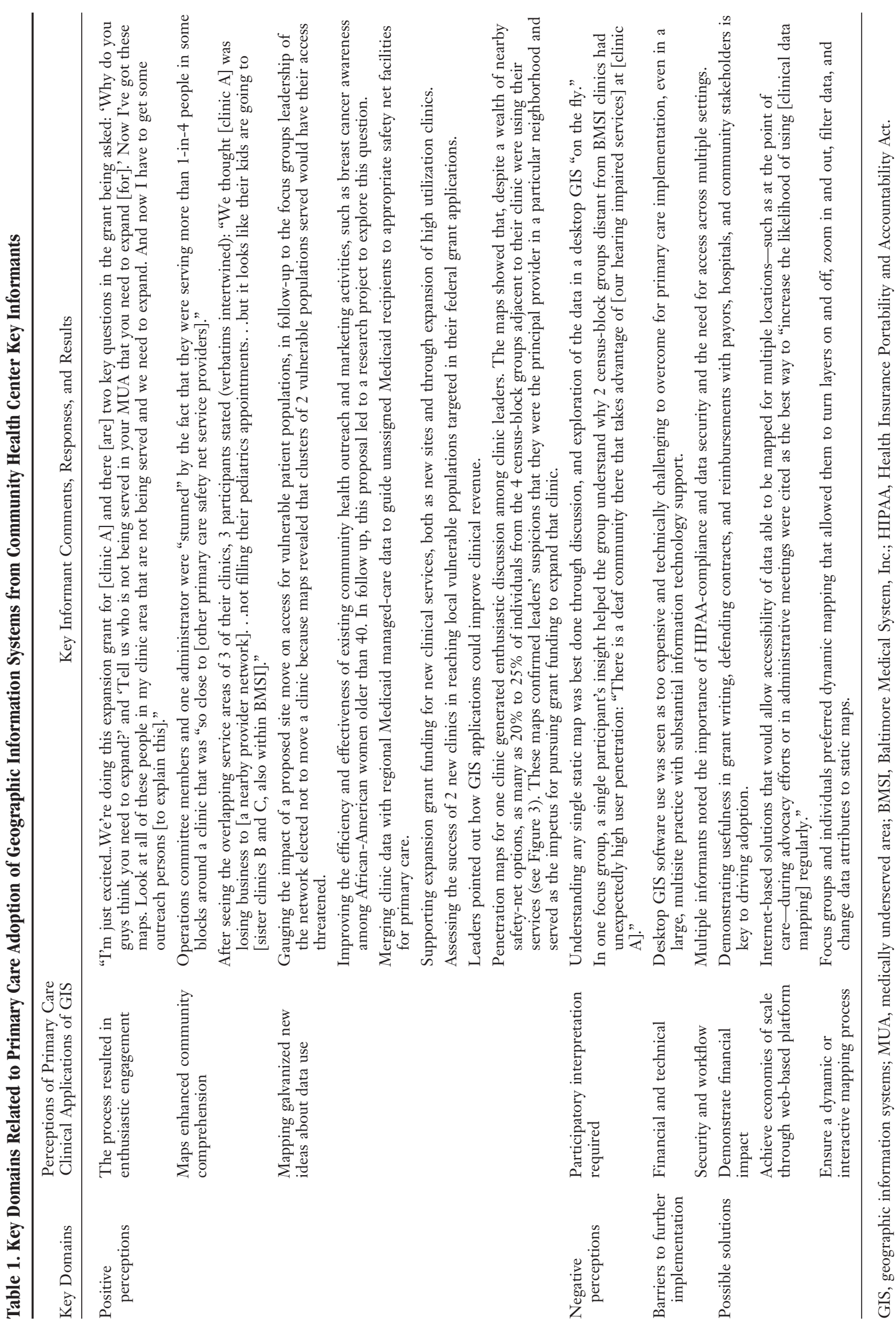


Figure 4. Perceptions, barriers, and possible solutions to increase primary care geographic information systems adoption. BMSI, Baltimore Medical System, Inc.; CHC, community health center.

\section{Highlandtown Community Health Center Patient Penetration by Block Group (Patient / Population)}

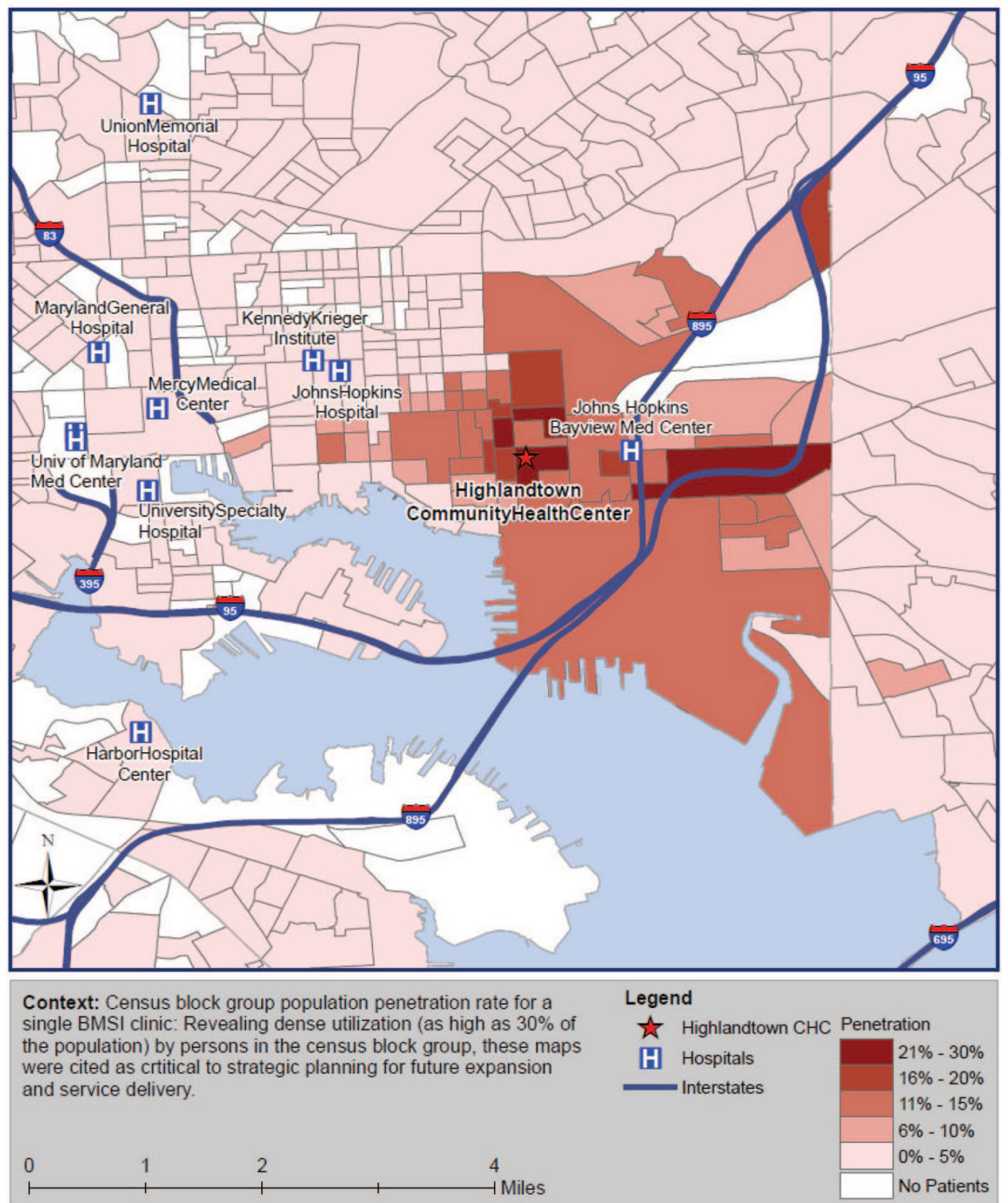

Whether findings of our exploratory evaluation of a single, large, multiclinic network that provides primary care to an ethnically and racially diverse population represent broader perspectives merits further study, but our early work with an array of primary care sites has yielded similar results. Although we cannot claim to have represented all clinical and administrative leaders from the organization used for our interviews and focus groups, purposeful and strategic sampling was used to ensure breadth. Additional studies in other settings (eg, rural, suburban, single-practitioner practices, multispecialty practices) are needed to confirm the usefulness of these techniques in wide array of clinical settings. Finally, as we learned from the tendency of our informants in this study, it is essential to understand the pitfalls and limitations of mapped data, which risks misinterpretation similar 
to and often beyond other forms of data display. Expanded use of GIS to inform planning and policy in the clinical setting will require users to consider issues such as data quality, geocoding match rate, the choice of appropriate scale and areal units, as well as issues of causality versus association, and will probably benefit from additional training or partnership with spatial methodologists.

\section{Conclusion}

Our longitudinal experience with this CHC network since conducting these interviews includes continued requests for new maps, request for a contractual relationship to continue their production, and specific application of mapping in planning future service delivery and expansion, clinic moves, and community outreach. Leaders at BMSI have expressed the opinion that this exercise would be measurably more valuable if all safety-net services were similarly mapping their communities and could collaborate on regional planning. However, broader application of these methods is limited by the lack of financial and technical capacity in CHCs and other primary care settings, a theme identified by $\mathrm{CHC}$ leaders as a barrier to sustainability of our collaborative mapping project. Commercially available technologies now permit geocoding and housing of outpatient clinical data in a Health Insurance Portability and Accountability Act-compliant fashion; user-friendly internet mapping software have improved substantially in recent years. Such software may offer the ability to overcome the barriers to GIS use cited by clinic leaders and to realize GIS economies of scale for a large body of health centers or primary care clinics, expanding the reach of clinical analytic mapping to CHCs nationwide. Healthy People 2010 calls for an "increase in the proportion of all major national, state, and local health data systems... to promote nationwide use of GIS at all levels," with a goal of $90 \%$ use in such systems. ${ }^{24}$ Policy makers and regional planners supporting CHCs should consider policies and incentives that broaden GIS implementation at the clinical level.

We gratefully acknowledge the assistance of Baltimore Medical Systems, Inc., staff, in particular that of Michael Barr and Jay Wolvowsky, as well as Imam Xierali for his assistance in map production and Lisette Dunham for her help in preparing this manuscript for submission.

\section{References}

1. DeNavas-Walt C, Proctor BD, Lee CH, US Census Bureau. Income, poverty, and health insurance coverage in the United States: 2004. August 2005. Available at www.census.gov/hhes/www/hlthins/hlthin05. html. Accessed 30 October 2009.

2. US Department of Health and Human Resources, Health Resources and Services Administration. The Health Center Program: the President's health center initiative. Available at http://bphc.hrsa.gov/presi dentsinitiative/. Accessed 24 October 2009.

3. Miranda ML, Silva JM, Overstreet Galeano MA, et al. Building geographic information system capacity in local health departments: lessons from a North Carolina project. Am J Public Health 2005;95: 2180-5.

4. Fryer GE, Drisko J, Krugman RD, et al. Multimethod assessment of access to primary medical care in rural Colorado. J Rural Health 1999;15:113-21.

5. Andrews JW, Hames CG, Metts JC Jr, Waters L, Davis JM, Carpenter R. Relationships between selenium and other parameters in drinking water and blood of subjects from high and low cardiovascular disease rate areas of Georgia. J Environ Pathol Toxicol 1980;4:313-8.

6. Farley ES Jr, Boisseau V, Froom J. An integrated medical record and data system for primary care. Part 5: Implications of filing family folders by area of residence. J Fam Pract 1977;5:427-32.

7. Guagliardo MF. Spatial accessibility of primary care: concepts, methods and challenges. Int $\mathrm{J}$ Health Geogr 2004;3:3.

8. Phillips RL Jr, Kinman EL, Schnitzer PG, Lindbloom EJ, Ewigman B. Using geographic information systems to understand health care access. Arch Fam Med 2000;9:971-8.

9. Phillips RL, Bazemore A, Miyoshi TJ. Tools for monitoring the health care safety net. Mapping tools for monitoring the safety net. Rockville, MD: Agency for Healthcare Research and Quality; 2003.

10. Bazemore A, Phillips RL, Miyoshi TJ. Using geographic information systems to define healthcare access in an urban community health center network. Available at http://proceedings.esri.com/library/ userconf/health03/papers/pap3037/p3037.pdf. Accessed 30 October 2009.

11. Simpson K, DesHarnais S, Acobs A, Enapace A. Methods for defining medical service areas. In: Ricketts TC, Savita LA, Gesler WM, Osborne DN, Lanham MD, eds. Geographic methods for health services research. Lanham, MD: University Press of America; 1994:207-32.

12. Johnson JC. Selecting ethnographic informants. Newbury Park, CA: Sage Publications; 1990.

13. Crabtree BF, Miller WL. The analysis of narratives from a long interview. In: Stewart M, ed. Tools for primary care research. Newbury Park, CA: Sage Publications; 1992:209-20. 
14. Kawachi I, Berkman LF, eds. Neighborhoods and health. New York, NY: Oxford University Press, USA; 2003.

15. Gofin J, Gofin R. Community-oriented primary care and primary health care. Am J Public Health 2005; 95:757.

16. Kark SL. Epidemiology and community medicine. New York, NY: Appleton-Century-Crofts; 1974.

17. Donaldson M, Yordy KD, Lohr KN, Vanselow NA. Primary care: America's health in a new era. Washington,DC: National Academy Press; 1996.

18. Institute of Medicine. Crossing the quality chasm: a new health system for the 21st Century. Washington, DC: National Academy Press; 2001.

19. Phillips RL, Mullan F, Kinman E. Geographic retrofitting: a method for community definition. Presented at the $130^{\text {th }}$ Annual Meeting of the American Public Health Association, Philadelphia, PA, 9-13 November 2002.

20. Phillips RL, Parchman ML, Miyoshi TJ. Using geographic information systems to understand health care access. Available at http://proceedings.esri.com/ library/userconf/health01/papers/hc01_p01d/ hc01_p01d.html. Accessed 24 October 2009.

21. US Department of Health and Human Services. HHS continues health care safety net expansion. Awards $\$ 4.9$ million to create new or expand existing health centers. Available at http://www.dhhs.gov/ news/press/2002pres/20021004.html. Accessed 30 October 2009.

22. Crump RL, Gaston MH, Ferguson G. HRSA's models that work program: implications for improving access to primary health care. Health Rep 1999;114:218-24.

23. US Department of Health and Human Services, Health Resources and Services Administration. HRSA Geospatial Data Warehouse. Primary care service areas-2006 edition. Available at http:// datawarehouse.hrsa.gov/pcsa2006.aspx. Accessed 30 October 2009

24. US Department of Health and Human Services. Healthy People 2010: understanding and improving health, 2nd ed. Available at http://www.hhs.gov/news/press/2000 pres/20000125a.html. Accessed 24 October 2009. 